\title{
LA AVELLANEDA, EL VALOR DE UN “LA” ANTEPUESTO A UN
}

\author{
APELLIDO: "LLAMADME TULA"1
}

\author{
Francisco Javier Gil Jacinto ${ }^{2}$
}

\section{La Avellaneda, el valor de un "la" antepuesto a un apellido: "llamadme Tula"}

Resumen: Este trabajo analiza la presencia del artículo la antepuesto al apellido Avellaneda en los títulos de algunas monografías referidas a la escritora y, también, cómo este uso ha servido en ocasiones para señalar la preeminencia o inferioridad de otras mujeres. Igualmente, se señalan las asociaciones realizadas por la crítica entre el sexo y la personalidad de la autora en confluencia con el uso o no del artículo. El estudio está centrado en las obras de Cotarelo (1930) y BravoVillasante (1986), en la bibliografía citada por ellos, y en otra más reciente donde la tendencia observada es la supresión del artículo.

Palabras claves: La Avellaneda, género gramatical, Romanticismo, literata, poetisa, bovarismo, criolla.

La Avellaneda, the Value of "la" before a Surname: "Call me Tula"

Abstract: This essay analyses the inclusion of the Spanish feminine article la preceding the surname Avellaneda in the titles of some writings about that author. The feminine determiner before women's" surnames may denote excellence, but it can also carry negative connotations. The essay also underlines the association made by some critics between the feminine article and the personality of a poetess. The research concentrates on the work of Cotarelo (1930) and BravoVillasante (1986), and references the modern tendency to drop the la determiner.

Keywords: La Avellaneda, grammatical gender, Romanticism, bluestocking, poetesses, bovarism.

En 1930 el académico y secretario perpetuo de la Real Academia Española, don Emilio Cotarelo y Mori, publicaba un trabajo sobre la vida y la obra de Gertrudis Gómez de Avellaneda, y lo abría con las siguientes palabras a modo de "advertencia":

Doña Gertrudis Gómez de Avellaneda es, no solamente la primera poetisa de España, sino una de las más grandes, acaso la más, entre las que han sobresalido en todo el mundo, en los géneros lírico y dramático. Modernamente la han dado a conocer algunos eruditos como escritora de cartas, y tampoco en este género cede

\footnotetext{
${ }^{1}$ Fecha de recepción: 08/11/2016.

Fecha de aceptación: 05/12/2016. ${ }^{2}$ Doctorando del Programa de Doctorado en Estudios Filológicos y Asistente honorario del Departamento de Lengua Española, Lingüística y Teoría de la Literatura de la Universidad de Sevilla; $\square$ masefo@yahoo.es.
} 
la palma a ninguna otra. [...] Bien merece, pues, que se le dediquen biografía y estudios críticos extensos, que mejoren y completen el presente. (Cotarelo 1930: 6)

$\mathrm{Y}$ es justamente lo que ha venido sucediendo a juzgar por el amplio número de publicaciones aparecidas desde entonces en torno a la autora. Pero ya eran muchas las que se le habían dedicado antes de 1930, entre las cuales llama la atención que haya un alto porcentaje que en sus títulos, incluida la del propio Cotarelo, se refieran a la escritora por el apelativo de La Avellaneda en sus títulos. Por lo que, sin pretender ser exhaustivo, se podrían citar los siguientes por orden cronológico a modo de ejemplo: Biografía de la Avellaneda (Anónimo 1844); "sobre la Avellaneda" (Fornaris 1883); "Biografía y estudio crítico de la Avellaneda" (Mitjans 1890); La Avellaneda. Autobiografia y cartas de la ilustre poetisa (Córdoba 1907); De la Avellaneda. Colección de artículos (Rodríguez 1914); La Avellaneda y sus versos (López 1928); y la de Cotarelo, La Avellaneda y sus obras (1930). Más otras tantas que podrían señalarse posteriores a ésta fecha.

En un principio cabría suponer que el artículo la antepuesto a Avellaneda está relacionado con la precisión que se hace en el Diccionario Panhispánico de Dudas de que, aunque los nombres de personas no lo lleven, "en todo el ámbito hispánico es habitual que los apellidos de mujeres célebres vayan precedidos de artículo", sería el caso de la cantante de ópera La Caballé, por ejemplo ( $D P D$, s. v. el). Sin descartar esa posibilidad también para las escritoras de renombre, cabría preguntarse entonces por qué Cotarelo, en un mismo párrafo de su obra, decide anteponerle el artículo a Avellaneda, pero no así a Fernán Caballero (1930: 38). Tampoco lo hace luego con "la poetisa malagueña Doña Dolores Gómez de Cádiz” (1930: 84) ni con “doña María Rosa Gálvez de Cabrera" (1930:176).

Esa ausencia de artículo, sin menos cabo de que pueda existir alguna excepción de lo contrario, parece ser una constante en los trabajos críticos referidos a Fernán Caballero, como se puede observar en el de Asensio, Fernán-Caballero: estudio biográfico (1893), o el de Montoto, Fernán Caballero: algo más que una biografía (1969). Dicha tendencia se constata igualmente en los títulos de obras referidos a otras escritoras de la época, de ese modo podemos encontrar: La familia de Carolina Coronado: los 
primeros años en la vida de una escritora (Fernández-Daza 2011), o Los cuentos de Emilia Pardo Bazán (Paredes 1979). Si bien es cierto que en alguna lección magistral o conferencia es posible que alguien se refiera a la Pardo Bazán con artículo, no es tan frecuente que luego pase a la escritura con tal apelativo, a no ser por motivos estilísticos.

En lo que no parece haber dudas al respecto es en que lo habitual sea referirse a las escritoras por el apellido, o por este precedido del nombre de pila; así decimos Martín Gaite y Ana María Matute. Por lo cual, el hecho de existir un caso como el de Avellaneda, en el que la oscilación parece depender del crítico que la mencione, bien merece un cierto detenimiento por si pudiera haber cierta carga peyorativa en ello. Tal parece ser así, que entre la crítica actual, y no sólo la feminista, quizás en un intento de subsanarlo, se observa un abandono de dicho artículo y una reivindicación de su nombre completo. A modo de ejemplo se pueden citar obras como: Gertrudis Gómez de Avellaneda. Memorias de una mujer libre (Ciro / Casado 2008); Autobiografía di donna Gertrudis Gómez de Avellaneda (Arriaga 2005); Género poesía y esfera pública. Gertrudis Gómez de Avellaneda (Albin 2002); El discurso de Gertrudis Gómez de Avellaneda: identidad femenina y otredad (Pastor 2002); El teatro de Gertrudis Gómez de Avellaneda (Prado 2001) o Gertrudis Gómez de Avellaneda: la dolorida pasión (Giménez 1999), para no hacer la relación demasiado extensa.

Con independencia de las motivaciones que los críticos pudieran haber tenido, tanto a la hora de incluir el artículo delante del apellido de la autora como de omitirlo, no cabe duda de que tiene un valor significante. Para empezar, se trata de resaltar, con la intención que sea, la marca de género, algo que no es necesario ni habitual en el caso de los autores masculinos, pero es muy posible que lleve asociado algún otro sentido. De momento, en la bibliografía recogida por Cotarelo, los títulos en los que aparece el sintagma La Avellaneda suelen hacer alusión a su biografía personal o a algún aspecto relacionado con esta, como el artículo "Una tragedia real de la Avellaneda" (1926), escrito por él mismo. Pero si nos atenemos a la edición de su estudio de 1930 al que nos hemos venido refiriendo, hay que señalar que el título impreso en su portada es el de $L a$ Avellaneda, aunque dentro, en la portadilla, aparezca también un y sus obras, seguido de un subtítulo que reza Ensayo biográfico y crítico. Así pues, si tuviéramos que guiarnos 
por el orden de esos dos adjetivos, lo personal iría por delante de lo textual, o al menos formando un tándem. Da la impresión entonces de que cada vez que aparece dicho apelativo en el título de alguno de los trabajos referidos, sus autores han querido resaltar ciertos aspectos personales de la escritora mediante el recurso de establecer un vínculo entre su personalidad y la marca de género; en muchos casos asociado a una valoración negativa.

En un intento de apoyar la idea anterior, pensemos por ejemplo en la obra de Cotarelo, que recordemos lleva por título La Avellaneda y sus obras (1930), y donde efectivamente dedica bastante espacio a analizarlas. Ahora bien, en once de sus veintiún capítulos se ocupa al mismo tiempo de la situación amorosa de la autora. Piénsese sin embargo en la poca importancia que la vida sentimental de los autores masculinos suele tener en la valoración de sus obras.

Otro trabajo que puede citarse para ahondar en los valores asociados que el artículo determinado femenino puede tener, además del de servir de marca de género, es el de Mercedes Ballesteros Vida de la Avellaneda (1949). En este caso bien puede decirse que el uso de la está justificado para identificar el sexo de la persona, habida cuenta de que dicha obra está editada dentro de la "Colección Hombres e Ideas”. Pero aunque aquí resulte tentador discutir el tópico del talento varonil que muchos críticos le han atribuido a Gómez de Avellaneda, y de la cual se hace eco Cotarelo (1930: 197), baste con señalar lo llamativo que resulta ver en la cubierta del libro de Ballesteros el contraste entre lo masculino y lo femenino, con lo que parece estar queriendo advertir al lector desde su portada que se trataba de una mujer fuera de lo ordinario ya por el simple hecho de estar ocupando un lugar reservado a los hombres.

Esa idea de la existencia de unos espacios netamente masculinos y otros que solo se insinuaban en la portada de la obra de Ballesteros van a hacerse totalmente explícitos ya en la primera página. Allí, la autora, a manera de lección moral, advierte al lector, y sobre todo a las lectoras, por si alguna pensaba seguir los pasos de la escritora, de que las extravagancias se pagan, "porque es dolorosa ley de las mujeres que triunfan ante el público el que guarden una intimidad fracasada, hecha de sinsabores y desengaños" 
(Ballesteros 1949: 9). Estos sufrimientos, naturalmente, tienen, en el caso de Gertrudis, nombres de varones: Loymaz, Francisco Ricafort, Ignacio Cepeda y Gabriel García de Tassara sobre todo. Todos ellos, al parecer, fueron los responsables de que esta biografía se cierre diciendo que cada vez que se hable de literatura romántica ya no podrá dejar de mencionarse a esta "egregia mujer que lo consiguió todo en la vida, menos la felicidad" (Ballesteros 1949: 134).

Justamente, el apelativo de romántica, usado con un sentido más amplio que el de delimitar un periodo literario, es el que emplea Carmen Bravo-Villasante para calificar la vida de Gómez de Avellaneda en una biografía que, siguiendo la estela de las de Cotarelo y Ballesteros, incluye también el determinante antepuesto al apellido de la escritora: Una vida romántica: la Avellaneda (1986). En dicho trabajo, además de citar las monografías de los otros dos críticos, menciona a una veintena de ellos que han incluido en sus títulos el apelativo La Avellaneda, junto a otra treintena que se refiere a ella de manera diferente. Al tratarse Bravo-Villasante de una reconocida autora de biografías, entre las que viene a colación citar las de Vida de Bettina Brentano (1957) y Emilia Pardo Bazán: vida y obra (1962), por ser ambas mujeres e ir sin el determinante, es de suponer que cuando se decidió a agregárselo a Avellaneda, debió ser o bien con la intención de caracterizarla de alguna manera determinada, o bien simplemente porque se dejó llevar por una costumbre iniciada en 1842 en el periódico El Álbum de Caracas con un artículo anónimo titulado "Biografía de la Avellaneda" (Cotarelo 1930: 405).

A la moda de nombrar a la escritora cubana como La Avellaneda, ya hemos visto que se le fueron sumando muchos biógrafos y algunos críticos, aunque es necesario recordar que un periódico de la época se referían a ella como "nuestra distinguida colaboradora doña Gertrudis Gómez de Avellaneda" (Cotarelo 1930: 67), y que lo normal es que lo hicieran por los nombres de "la señorita de Avellaneda"; "señora doña Gertrudis Gómez de Avellaneda", "señora Avellaneda"; "señorita Avellaneda"; e incluso con el tratamiento de "excelentísima señora doña Gertrudis Gómez de Avellaneda, viuda de Savater” o “doña Gertrudis”, según muchas de las críticas recogidas por los diarios de la época mencionadas por Cotarelo (1930: 67, 104, 125, 152, 180, 187, 205). El uso del apelativo La Avellanada en una reseña negativa a su drama La Sonámbula que fue 
publicada en el Diario de Madrid de manera anónima (Cotarelo 1930: 265) parece ser más una excepción que una regla, y el hecho de que no fuera firmada da entender que tal empleo del mismo conllevaría un matiz despectivo.

Por otra parte, es preciso señalar que en vida de la autora, ésta publicó sus novelas y sus dramas, como Espantolino (1958) o El Príncipe de Viana (1844), con el nombre de señorita Avellaneda, Señorita Gómez de Avellaneda o Gertrudis Gómez de Avellaneda. De ese modo están publicados también los seis volúmenes de Obras literarias de la Señora Doña Gertrudis Gómez de Avellaneda (1869-1871); las Poesías de la Señorita Gertrudis Gómez de Avellaneda (1841); y su Devocionario nuevo completísimo en Prosa y verso (1867). Además de que su modo de firmar era $G$. G de A., Gertrudis o Tula, tal y como se observa en las cartas autobiográficas que le enviaba a Cepeda (Gómez de Avellaneda 2006 [1906]).

Estos datos relativos a la manera en que la prensa y las imprentas de su época trataban a Gómez de Avellaneda eran sin duda conocidos por Bravo-Villasante, puesto que han sido tomados en su mayoría de fuentes citadas también por ella en su biografía sobre la autora. De ser esto cierto, y si nos atenemos a las indicaciones del Diccionario panhispánico de dudas ya citado, de que la presencia del artículo delante de algunos nombres célebres de mujer convierte automáticamente al género femenino en el marcado frente al masculino que sería el neutro, la intención de su biógrafa al anteponer un la al apellido Avellaneda sería la de subrayar alguna cualidad que en principio, acaso por ser mujer, no se debería presuponer a quien la lleva.

Para ilustrar lo anterior con un ejemplo, pensemos en el caso de la humanista Beatriz Galindo, la que fuera también preceptora y profesora de latín de Isabel la Católica, toda una rareza según los parámetros del siglo XVI, lo cual era necesario marcar de alguna manera, de ahí el sobrenombre de La Latina. Aún más, lo que resulta significativo es que dicho apelativo ha terminado convirtiéndose en un término académico para referirse de manera general a un tipo de mujeres que se consideran privilegiadas por haber podido acceder a la universidad y recibir una educación en condiciones excepcionales, "las latinas" (Caballero 2012: 25). Ello no quita, para que a las féminas formadas o con 
veleidades literarias se les haya calificado a veces con sobrenombres como el anterior, que se convierten en despectivos solo al ser usados en su forma femenina. De este modo el adjetivo literato mantiene la carga apreciativa para el varón, pero no cuando se lo aplicaban las de Ozores a su sobrina en la conocida novela de Clarín, La Regenta (1884): "una cosa hombruna, un vicio de hombres vulgares [...] ¡Una Ozores literata!” (cap. V). Del mismo modo que en la vida real las parientas gallegas de Gertrudis se mofaban de su afición al estudio y "la llamaban en burla la Doctora [...] y exageraban su ignorancia en cosas mujeriles" (Cotarelo 1930, 24).

Fuera del ámbito de la excelencia, el uso del artículo antepuesto al nombre propio, con la excepción de algunos ámbitos geográficos perfectamente delimitados, su uso se vincula siempre al uso popular, coloquial y para referirse a las mujeres. Son abundantes los ejemplos que aparecen ligados al mundo de la copla o del género de variedades, tales como Consuelo Portela, "la Chelito"; Carolina Otero, "La Bella Otero"; Encarnación López Júlvez, "La Argentinita”; Concha Piquer López, "La Piquer”; o Dolores Parrales Moreno, "La Parrala". Eso en cuanto a las cantantes, porque entre las protagonistas de algunas de las coplas que interpretaban encontramos "La Lirio", "La Caramba", "La Salvaora", "La Zarzamora" y "La Loba” (Hurtado 2006).

También dos de las mejores obras de la tradición literaria española llevan por título nombres de mujeres precedidos por el artículo: La Celestina (1499) de Fernando de Rojas y La Regenta (1884) de Leopoldo Alas, Clarín, antes mencionada. El matiz negativo de la alcahueta cose-virgos casi no es preciso comentarlo, y la ironía del segundo por parte de su autor y de los paisanos de Anita Ozores, con independencia de la simpatía que despierte en los lectores, queda de manifiesto en la novela.

Pero no hace falta circunscribirse al mundo de la literatura o de los géneros musicales ligeros para encontrar ejemplos del uso despectivo, o al menos intencionado, del artículo antepuesto a un nombre femenino, porque esta es una práctica que también se da en la política. Aunque en las tertulias radiofónicas o televisivas sea frecuente escuchar a algún periodista referirse a "La Cospedal" o a "La Merkel", es difícil sin embargo encontrarlas por este nombre en la prensa escrita, quizás porque lo prohíba el 
libro de estilo de los periódicos. No ocurría lo mismo en el pasado, pues la prensa, tanto la conservadora como la liberal de la década de los 70, se refería, por ejemplo, a la presidenta del Partido Comunista español como La Pasionaria, bien en un almuerzo con el dirigente de Yugoslavia, Tito, ( $A B C$ 1976), bien en su participación en un mitin en Mieres (Diario 16 1976).

Como han demostrado las diferentes ramas de la lingüística a lo largo del siglo XX, no hay nada en la lengua que sea redundante, inocente o gratuito. Igualmente, el artículo el artículo determinante delante de algunos nombres o apellidos femeninos tampoco lo es, ni en los casos que se han apuntado anteriormente, ni en el caso concreto de Gertrudis Gómez de Avellaneda. Para analizar este fenómeno en profundidad podemos volver de nuevo en la biografía de Bravo-Villasante (1986). En primer lugar, por tratarse esta de una obra que no se haya tan alejada temporal ni ideológicamente como la de Cotarelo (1930) o Ballesteros (1949). Y en segundo, por no ser tampoco tan reciente como para recoger en ella las últimas aportaciones hechas a la autora desde la perspectiva de la crítica de género. Esa equidistancia permite realizar un acercamiento imparcial a la visión que durante un siglo se ha mantenido en los círculos académicos acerca de su persona y de su producción literaria

Quizás lo apropiado sea entonces comenzar por el adjetivo de la primera parte de la estructura bimembre de su título: Una vida romántica: La Avellaneda. El Diccionario de la Real Academia Española [DRAE] lo relaciona en tres de sus acepciones con el movimiento romántico, en cuyas filas militó Gómez de Avellaneda, pero incluye también una cuarta que da la definición de "sentimental, generoso y soñador" (DRAE, s. v. romántico), y para la de sentimental da la de "exagerado en la expresión de sus sentimientos" (DRAE, s. v. Ídem). Por otra parte, hay que tener en cuenta que los escritores románticos ya eran objeto de chanzas en tiempos de la escritora. Baste recordar el tono satírico del capítulo "El Romanticismo y los románticos" en Escenas y tipos matritenses (1851) de Mesonero Romanos que se abre además con los siguientes versos de Lope de Vega, los cuales hacen referencia a la pérdida de la cordura:

Señales de juicio son ver que todos lo perdemos 
unos por cata de más

y otro por cata de menos.

Por esa misma época, Leonardo Alenza, pero con los pinceles en lugar de con la pluma, tanto en su cuadro Los románticos como en el de Sátira del suicidio, los dos de 1837 y expuestos hoy ambos en el Museo del Romanticismo de Madrid, daba una imagen un tanto esperpéntica, de los escritores románticos como personas con la razón trastornada.

Esto en ningún caso quiere decir que la autora de la biografía, o la editorial que la encargó, esté intentando mandar ese mensaje implícito ya desde la portada, pero si al adjetivo romántica de la cubierta se le añaden los del interior de impetuosa, indómita, iracunda, colérica, teatrera, febril, furibunda, arrebatada, furiosa, singular, desconcertante, violenta, imprevisible, atormentada, dificil y, finalmente, el de loca, aunque no sea en su sentido clínico, el lector pude sentirse inclinado a pensar que la protagonista sí lo estaba. Además, en sus páginas se establecen también ciertos paralelismos entre Avellaneda y otros personajes de ficción, como la Julia de Lamartine, que incita a su amante "a una muerte romántica voluntaria", o la Corina de Madame de Stäel, "que casi al mismo tiempo pasaba de la melancolía al contento" (Bravo-Villasante 1986: 47 y 49); comparaciones que sirven para poner en duda la salud mental de la aludida.

Por otro lado, para explicar las relaciones difíciles de Gertrudis y de su hermano con su madre y con su padrastro, Bravo-Villasante echa mano de la mitología y de la teoría psicoanalítica de Freud para asignarle a cada uno los papeles de Electra, Orestes, Clitemnestra y Agamenón, respectivamente (1986: 17). El dato en sí es anecdótico, y puede no tener más pretensiones que las de ser una mera licencia poética por parte de la filóloga, pero el salto de la literatura a la psicología clínica acaba de producirse en el primer capítulo; ello sin contar con que las referencias al "afán insano" de esta "turbulenta" niña cubana estaban ya presentes en la introducción a la obra, por lo que, a partir de aquí, referirse a ella con tal o cual etiqueta médica va a costar un poco menos.

A lo largo de toda la obra, Bravo-Villasante va a seguir insistiendo, por un lado, en el temperamento voluble de Gómez de Avellaneda, "exuberante siempre en todo", y, por el otro, en su incapacidad para distinguir entre el teatro y la vida: "vive en la ficción, 
el mejor remedio para la desgracia, y si las ficciones teatrales son trágicas, se identifica mejor con las víctimas" (1986: 18). Una idea que seguirá repitiendo al final de la obra, "porque como pura romántica, se ve siempre como actriz de una comedia o un drama" (1986: 188). La paradoja es que será ella misma, la biógrafa, quien necesitará acudir una y otra vez a la literatura para describir el comportamiento de la biografiada. De su Leoncia dirá que "hay como un vaticinio del futuro de la Avellaneda" y que, a pesar del romanticismo infernal que desprenden sus exclamaciones, "comprendemos que el romanticismo es verdad" (Bravo-Villasante 1986: 55). Más adelante, tras describir a Rosa, la protagonista de La flor del ángel, como "una mujer que cede a los deseos de venganza, que luego la perjudican", añade que así imaginaba que era la Avellaneda: "una turbulencia enrojecida debía nublar su vista en los momentos de ira" (Bravo-Villasante 1986: 183). E incluso recurrirá a tópicos del Romanticismo como el de la fuerza del destino, el del ansia de lo infinito o el del mal del siglo para explicar el comportamiento de su biografiada. Es la fatalidad, sostiene Bravo-Villasante, la que en consecuencia impide que el placer y la felicidad de Gertrudis sean completos, y para apoyar tal afirmación selecciona unos versos del último poema de su libro Poesía:

Pero es un mal terrible, sin remedio.

Que hace odiosa la vida, odioso el mundo.

Que seca el corazón... En fin, es el tedio! (Bravo-Villasante 1986: 62).

Las citas anteriores son una indicación de lo tentador que resulta atribuirle a un individuo los rasgos definidores de un arquetipo, y de lo difícil que es en este caso separar a Gómez de Avellaneda del prototipo de heroína romántica, pues buena parte de la crítica literaria ha querido ver en ella la encarnación más fiel del modelo. Si pensamos en los atributos propios de los personajes románticos, ella los acumularía todos, y en su biografía Bravo-Villasante no pierde ocasión de incidir en ellos. Uno de esos rasgos es, por ejemplo, el de poseer una imaginación desbordada alimentada por incasables lecturas, de modo que no sólo "recorre las librerías y compra libros de moda. Leila e Indiana son las últimas novedades", sino que, atención al matiz, "se embebe de romanticismo [...]. Todo el día es poco para leer y para ver, toda la noche transcurre entre representaciones teatrales y musicales" (Bravo-Villasante, 1986: 32). 
Va a ser Gustave Flaubert quien en Madame Bovary (1856), una vez apagado el fuego romántico, denuncie las consecuencias del exceso de imaginación y del de ciertas lecturas, algo de lo que ya nos había avisado Cervantes con Don Quijote de la Mancha (1605) dos siglos antes, aunque el término clínico bovarismo (Gaultier 1902) se haya hecho derivar del personaje femenino, mientras que el de quijotismo, tiene cierta carga positiva e idealista.

Relacionado con lo anterior y con la configuración de modelos femeninos estereotipados en general, y no exclusivamente el de la escritora romántica del que nos estamos ocupando ahora mismo, es preciso mencionar La loca del desván: la escritora y la imaginación literaria del siglo XIX (Gilbert y Gubar 1998), donde sus dos autoras, al abordar el modelo de la loca que ha quedado plasmado en la literatura del siglo XIX, mencionan el caso de Bertha Mason, personaje de la novela de Charlotte Brote, Jane Eyre (1847), que no es otra que la Antoinette Cosway de Ancho mar de los Sargazos (1996) de Jean Rhys. Según Michael Thorpe en “'The Other Side': Wide Sargasso Sea and Jane Eyre", el personaje de Bertha ha sido siempre denostado, debido a prejuicios raciales que ligan su locura al hecho de haber nacido en las Indias Occidentales y a su sangre criolla. Este crítico insiste en que esa deshumanización del personaje le habría servido a Charlotte Brontë y a la prejuiciosa audiencia victoriana de la época para humanizar el de Rochester, el cual tendría en la locura y el origen geográfico de su mujer, la Mesalina india del capítulo XXVII, un motivo para confinarla en el ático de Thornfield (Thorpe 1977). Por tanto, una última explicación de la locura del personaje parece encontrarse en el origen caribeño; el mismo que Bravo-Villasante nos recuerda tiene Gómez de Avellaneda cuando la describe como una "perfecta criolla, exótica" (1986: 67), y un poco antes lo ha hecho diciendo que "una salvaje, romántica salvaje a la moda, que no acata las leyes sociales, rebelde a los prejuicios [...], un ejemplar único en la isla de Cuba" (1986: 27).

Esa procedencia caribeña es una circunstancia que va a compartir Gertrudis no solo con el personaje de Antoinette Cosway, sino con su creadora, Jean Rhys, nacida en 1996 en la isla de Dominica, entonces bajo el dominio británico. Si bien es cierto que el paralelismo entre ambas escritoras podría dar para otro trabajo, aquí lo que interesa señalar únicamente es la manera en que ambas sirven igualmente al modelo de autora 
colonial que viene al viejo continente, confunden vida y literatura, peregrinan de unas ciudades a otras, llevan una vida amorosa agitada, pasan periodos de aislamiento, y que presentan rasgos de carácter próximos a la locura según algunos críticos literarios. En cierto modo las biografías de la una y de la otra, la de Bravo-Villasante (1989) y la de Carole Angier (1985), podrían leerse de forma paralela. En las dos se hace un relato de sus vidas partiendo de fuentes autobiográficas y de epistolarios, pero con sus obras siempre de fondo, con lo que en ocasiones existe la tentación por parte del lector de tomar por realidad lo que sólo es ficción literaria.

La imagen viajera de Avellaneda, apuntada anteriormente casa bien con la del vagabundo romántico inmortalizado en el cuadro de Caspar David Friedrich El caminante ante un mar de niebla (1818), tan del gusto de la época. Y esa es la descripción que su biógrafa nos va a ofrecer de ella, la de "una peregrina en la tierra [...] inquieta y errabunda, como los héroes de las novelas románticas" (1986: 27). Pero además del desasosiego espiritual del siglo que la impulsa a moverse de un lugar otro, parece haber otro de tipo más mundanal, una especie de manía en el sentido psicológico del término que la hace mudarse constantemente de casa. Bravo-Villasante insiste en ese dato y da la dirección completa de las diez que ocupa entre 1840 y 1840, "cada año en una casa distinta, y aun años como el 44 que ha mudado de casa tres veces", al tiempo que no se resiste a resaltar lo patológico de dicha conducta: “iqué peregrinación, qué inquietud!, es algo obsesionante que denota la intranquilidad continua de la poetisa, cansada de todo, exigente, y como huyendo de la estabilidad" (Bravo-Villasante,1986: 137).

Otro de los episodios recogidos por Bravo-Villasante con la intensidad de un drama romántico en el que "todo es trágico y miserable como en una tragedia" es el de un viaje de vuelta a España desde Francia con un marido moribundo que fallecería en el camino antes de llegar a la frontera, en el que "en su desesperación la Avellaneda cree volverse loca y se encierra en el monasterio de Loreto" (Bravo-Villasante 1986: 136). Esa escena, además de evocar el luto de las reinas viudas de la casa de Austria retiradas en los conventos, recuerda también a las locas del desván de Gilbert y Gubar, y cobra cirtos tintes de novela gótica: "durante las noches padece insomnio y ve el rosto de su pequeña niña muerta y Sabater [...]. De día sigue viendo esos pobres fantasmas silenciosos y 
lúgubres, quietos" (Bravo-Villasante, 1986: 137).

En este retiro Gómez de Avellaneda tuvo tiempo para recapacitar sobre su “azarosa vida y sobre su difícil carácter", además de que este tiempo supuso el comienzo su producción religiosa, en la cual se incluyen una serie de poemas sacros y un devocionario de uso particular del que desataca una "oración para domar la inclinación soberbia y violenta", el defecto principal de la escritora, según Bravo-Villasante (1986: 118). Pero de esa época, nos recuerda la biógrafa, se han encontrado también una serie de papeles con promesas de carácter supersticioso relacionados con el juego de la lotería "más propias de un alma primitiva y elemental que de una mujer culta", por si alguien tenía la tentación de compararla con Teresa de Cepeda y Las moradas (1577), obra escrita igualmente como una guía a través de la oración para el fortalecimiento del alma. En fin, que el misticismo de la escritora tendría su origen en "un alma angustiada, cristiana, pero con un fondo heredado de superstición pagana, propio de la tierra de origen" (BravoVillasante 1986: 116), y, aunque no lo añade Bravo-Villasante, parece desprenderse que también que en el gusto por el esoterismo romántico.

De muevo la localización geográfica vuelve a estar en la base del comportamiento poco ortodoxo que llevó toda su vida "la reina mora del Camagüey" (Rexach 1996), esta "hija del sol magnífica y opulenta" que dirá Bravo-Villasante (1986: 22), quién la compara a la fuerza de una catarata de ese continente americano donde todo es grandioso, y ella tan seductora y atractiva que el que está a su lado no puede permanecer tranquilo y desea estrecharla contra su pecho: "incita al amor, a la pasión fatal" (1986: 43). Esta y otras descripciones que de Gertrudis dejaron algunos hombres de la época dan a entender que se trata de una nueva Eva procedente del paraíso, que ahora parece situarse en la isla de Cuba; de la también bíblica Salomé; o del personaje de Margarita Gautier de La Dama de las Camelias (1848) de Dumas, contemporánea de Gertrudis.

Naturalmente, todos los datos y acontecimientos recogidos en la biografía de Bravo-Villasante tienen visos de ser ciertos, y de no serlo, habría que achacarle tal responsabilidad a la misma Avellanada, pues gran parte de la obra se compone de fragmentos de la autobiografía y de cartas de la autora con sus correspondientes 
comentarios. Ahora bien, la selección de los mismos es de incumbencia exclusiva de quien la ha llevado a cabo y luego los ha interpretado. En este caso, se han dado algunos ejemplos de cómo en ese proceso de escoger ciertos materiales y de desechar otros se ha tenido cierta predilección por elegir aquellos que servían para proyectar una imagen de la escritora como una poetisa romántica y exaltada al estilo de las que ella misma retrataba en sus dramas.

La propia introducción a la obra, en la cual imagina a una joven Gertrudis contemplando un atardecer, "sobre las montañas sombra y luz, nubarrones negros [...]", resulta una incitación al lector a compartir su agitado estado de ánimo y a adentrarse con ella en "la divina tormenta de la noche", que parece ser una metáfora de lo que fue su vida y se nos va a contar más adelante, pero que a grandes rasgos ha quedado expuesta en el título, pues si pensamos en la estructura sintáctica del mismo, Una vida romántica: la Avellaneda, se trataría en principio de una construcción de dos elementos en relación paratáctica con una finalidad más o menos estilística. Ahora bien, si nos atenemos al contenido, nos encontraríamos ante lo que el profesor Antonio Narbona denominó una subordinada adverbial impropia (1989: 81-82), en la cual el nexo habría sido sustituido por una pausa entonativa marcada aquí con los dos puntos, pero con sentido causal o condicional, que se podría leer como que la consecuencia de llevar una vida romántica es terminar siendo reconocida, no como la escritora Gertrudis Gómez de Avellaneda, sino como La Avellaneda, y que lo personal adquiera más relevancia que su obra poética.

En cualquier caso, ya se indicó anteriormente que el objeto de este trabajo no era el de emitir ningún tipo de juicio sobre el estudio biográfico de Bravo-Villasante, sino señalar únicamente que el uso del artículo delante del apellido de las mujeres puede implicar una valoración negativa de las mismas o de sus obras, aun cuando quienes los usen no sean conscientes de que con ese breve la están contribuyendo a ello.

Es probable también que las continuas denuncias sobre la discriminación sutil que ejerce el lenguaje hagan que los autores sean más cuidadosos a la hora de nombrar a las mujeres cuando se dispongan a escribir sobre alguna de ellas. Gertrudis Gómez de Avellaneda sería uno de esos casos, pero hay otros llamativos también como el de $L a$ 
Pasionaria, cuyo reconocimiento como figura histórica ha ido ligado tanto a la pérdida del artículo del apodo como a la restitución del nombre en algunas biografías que se han publicado sobre ella: Una española llamada Dolores Ibárruri (Pamies 1976); "Ibárruri, Dolores" (Juliá 1986); Dolores Ibárruri (Capellín 1986); Pasionaria y los siete enanitos (Vázquez 1995); Pasionaria: Dolores Ibárruri, Historia y símbolo (Cruz 1999).

Ahora bien, tan imperceptible como la marginación subrepticia que supone el uso de artículo en nombres de mujeres resulta la omisión del mismo en los que lo han incluido tradicionalmente. En este sentido, es más que probable que la inmensa mayoría de los asistentes a la exposición sobre la obra de Luisa Roldán, organizada en 2007 por el Patronato del Real Alcázar de Sevilla en el tercer centenario de su muerte, llevara por título simplemente Roldana. Dicha ausencia, reparadora a todas luces de la figura de Luisa, está en consonancia con la edición del catálogo de la muestra consistente en una serie de textos que funcionan a modo de estudio de la obra de la imaginera. De entre ellos destaca el titulado "ser mujer y artista en la España de la edad moderna", que se abre con la siguiente cita de Christine de Pisan (Cité des Dames, 1405), "Cómo se va a entender la vida de las mujeres, si todos los libros los escriben los hombres".

Todos los casos citados anteriormente en los que se verifica la pérdida del artículo femenino, y con ello las connotaciones que dicha marca de género lleva aparejadas, muestran que no se trata de una moda pasajera, sino de una toma de conciencia de que es necesario denunciar y desarticular los mecanismos sutiles de discriminación derivados del uso del lenguaje.

\section{Referencias bibliográficas:}

ABC. 1976. "Tito ofreció un almuerzo en honor de La Pasionaria". Madrid: $A B C .31$ de agosto de 1976. 4.

Albín, María C. 2002. Género poesía y esfera pública. Gertrudis Gómez de Avellaneda y la tradición romántica. Madrid: Trotta.

Angier, Carole. 1985. Jean Rhys. Barcelona: Mondadori. 
Anónimo. 1848. "Biografía de la Avellaneda". Caracas: Periódico El Álbum, tomo I, entrega V. Ed. Cotarelo, Emilio 1930: 405.

Arriaga, Mercedes. 2005. Autobiografia di donna Gertrudis Gómez de Avellaneda. Bari: Palomar

Asensio, José M. 1893. Fernán-Caballero: estudio biográfico. Madrid: España Moderna.

Ballesteros, Mercedes. 1949. Vida de la Avellaneda. Madrid: Ediciones Cultura Hispánica.

Bravo-Villasante, Carmen. 1986. Una vida romántica: La Avellaneda. Madrid: Ediciones Cultura Hispánica.

Caballero, María. 2012. Las trampas de la emancipación: literatura femenina y mundo hispánico. Madrid: Biblioteca Nueva.

Capellín, María J. 1986. Dolores Ibárruri (1916-1939), Memoria de Licenciatura bajo la dirección del doctor David Ruiz. Oviedo: Universidad de Oviedo.

Casado, Mar y Ciro, Andrés, eds. 2008: Gertrudis Gómez de Avellaneda. Memorias de una mujer libre. Madrid: Icaría.

Cotarelo, Emilio. 1930. La Avellaneda y sus obras. Madrid: Tipografía de Archivos. Olazaga.

1926. "Una tragedia real de la Avellaneda". Revista de la Biblioteca, Archivo y Museo del Ayuntamiento de Madrid. Madrid: tirada aparte, $4^{\circ}$. Ed. Cotarelo, Emilio 1930: 405.

Cruz, Lorenzo. 1907. La Avellaneda. Autobiografía y cartas de la ilustre poetisa. Huelva: Miguel Mora. Ed. Cotarelo, Emilio 1930: 405.

Cruz, Rafael, 1999. Pasionaria: Dolores Ibárruri, Historia y Símbolo. Madrid: Editorial Biblioteca Nueva.

Diario 16. 1977. "según La Pasionaria, el PCE y el PSOE, partidos de futuro". Madrid: Diario 16. 1 de enero de 1977. 3.

Fernández-Daza, Carmen. 2011. La familia de Carolina Coronado: los primeros años en la vida de una escritora. Almendralejo: Ayuntamiento de Almendralejo.

Fornaris, José. 1861. Biografía de la Avellaneda y cuatro poesías. La Habana: Imprenta de la Viuda de Barcina y Comp. Ed. Emilio Cotarelo 1930: 405.

Gaultier de, Jules. 1892. Le Bovarysme. La Psychologie dans l"ouvre de Flaubert. Paris : Libraire Léopold Corf. Fuente <gallica.bnf.fr. / > Biblioteque Nationale de France.

Gilbert, Sandra y Susan Gubar (eds). 1998. La loca del desván: la escritora y la imaginación literaria del siglo XIX. Madrid: Cátedra. 
Gómez de Avellaneda, Gertrudis. 1841. Poesías de la Señorita Gertrudis Gómez de Avellaneda. Madrid: Establecimiento tipográfico Calle el Sordo 11.

1844. El Príncipe de Viana por la señorita de Avellaneda. Madrid: Imprenta de don José Repullés. Ed. Cotarelo, Emilio 1930: 405.

. 1858. Espantolino, por doña Gertrudis Gómez de Avellaneda. Madrid: Imprenta de Luis García, editor. Ed. Cotarelo, Emilio 1930: 405. editorial.

1867. Devocionario nuevo completísimo en Prosa y verso. Sevilla: Sin

1869-1871. Obras literarias de la Señora Doña Gertrudis Gómez de Avellaneda. Seis volúmenes. Madrid: Imprenta de M. Rivadeneira.

Gorman, Robert. 1986. "Ibárruri, Dolores”, Santos Juliá, en Biographical Dictionary of Marxism. Londres: Manshell Publ. Ltd. 145-6.

Hurtado, Sonia. 2006. La copla. La poesía popular de Rafael de León. Málaga: Fundación Unicaja.

Jiménez, Luzmaría, 1999. Gertrudis Gómez de Avellaneda: la dolorida pasión. Madrid: Ediciones Torremozas.

López, Alberto. 1928. La Avellaneda y sus versos. Santander: José Martínez. Ed. Cotarelo, Emilio 1930: 405.

Mesonero de, Ramón. 1993. Escenas y tipos matritenses. Edición de Enrique Rubio Cremades. Madrid: Cátedra.

Mitjans, Aurelio, 1890. Biografía y estudio crítico de la Avellanda. Habana. Ed. Cotarelo, Emilio 1930: 405.

Montoto, Santiago. 1969. Fernán Caballero: algo más que una biografía. Sevilla: Gráficas del Sur.

Pamies, Teresa. 1976. Una española llamada Dolores Ibárruri. Barcelona: Edit. Martínez Roca.

Paredes, Juan. 1979. Los cuentos de Emilia Pardo Bazán. Granada: Universidad de Granada, Servicio de Publicaciones.

Pastor, Brígida, 2002. El discurso de Gertrudis Gómez de Avellaneda: identidad femenina y otredad. Murcia: Compobell.

Prado, María. 2001. El teatro de Gertrudis Gómez de Avellaneda. Madrid: Universidad Complutense de Madrid.

Rexach, Rosario. 1996. Estudios Sobre Gertrudis de Avellaneda: La reina mora del Camagüey. Madrid: Edit. Verbum. 
Rodríguez, José A. 1914. De la Avellaneda. Colección de artículos.

Rojas de, Fernando. 2001. La Celestina [edición de Peter E. Russell]. Madrid: Clásicos Castalia.

Thorpe, Michael. 1977. “'The Other Side': Wide Sargasso Sea and Jane Eyre” [ARIEL. A Review of International English Literature]. Wide Sargasso Sea. Jean Rhys. Ed. Judith Raiskin. New York: Norton and Company, Inc., 1999. 173-181.

Villaverde, Cirilo. 1942. "La señorita doña Gertrudis Gómez de Avellaneda". Habana: Faro industrial de la Habana págs. 8 y ss. Ed. Cotarelo, Emilio. 1930: 405.

Vázquez, Manuel. 1995. Pasionaria y los siete enanitos. Barcelona: Ed. Planeta. 